\title{
Emerging Role of Mucolipins TRPML Channels in Cancer
}

\author{
Giorgio Santoni ${ }^{1 *}$, Matteo Santoni ${ }^{2}$, Federica Maggi ${ }^{1,3}$, Oliviero Marinelli ${ }^{1,4}$ and \\ Maria Beatrice Morelli ${ }^{1}$
}

${ }^{1}$ Section of Immunopathology, School of Pharmacy, University of Camerino, Camerino, Italy, ${ }^{2}$ Medical Oncology Unit, Hospital of Macerata, Macerata, Italy, ${ }^{3}$ Department of Molecular Medicine, University of Rome Sapienza, Rome, Italy,

${ }^{4}$ School of Biosciences and Veterinary Medicine, University of Camerino, Camerino, Italy

Keywords: cancer, tumor progression, ion channels, transient receptor potential channels, mucolipins

\section{INTRODUCTION}

At the end of 2018, Faris and colleagues published an article in Cancers entitled "Endolysosomal $\mathrm{Ca}^{2+}$ signaling and cancer hallmark: two pore channels on the move and TRPML1 lags behind!" emphasizing the emerging role of two pore channels (TPC) in cancer, in contrast to that of comparable transient receptor potential mucolipin channel 1 (TRPML1) the role of which in cancer was still obscure (1).

TPCs and TRPMLs are endolysosomal channels regulating the autophagy/lysosome

OPEN ACCESS

Edited by:

Jan B. Parys,

KU Leuven, Belgium

Reviewed by:

Christian Grimm,

Ludwig Maximilian University of

Munich, Germany

Olivier Mignen,

Université de Bretagne

Occidentale, France

*Correspondence:

Giorgio Santoni

giorgio.santoni@unicam.it

Specialty section:

This article was submitted to Molecular and Cellular Oncology,

a section of the journal

Frontiers in Oncology

Received: 06 February 2020 Accepted: 08 April 2020

Published: 28 April 2020

Citation:

Santoni G, Santoni M, Maggi F, Marinelli $O$ and Morelli MB (2020) Emerging Role of Mucolipins TRPML

Channels in Cancer.

Front. Oncol. 10:659.

doi: 10.3389/fonc.2020.00659 system, which is strongly associated both with cancer progression and cancer escape from immunosurveillance. A role for TPCs in cancer cell invasiveness and metastasis has been established (2-4). Instead, regarding the TRPML channels, the evidence for their role in cancer was scarce until recently. At present this gap has been filled and findings until now are summarized in Table 1.

\section{TRPML CHANNELS}

TRPML1, TRPML2, and TRPML3 are non-selective cation channels belonging to the TRP channel family. These channels are encoded by MCOLN genes (MCOLN1, MCOLN2, and MCOLN3) located, respectively, on human chromosome 19 (19p13.2-13.3), chromosome 1 (1p22.3) and chromosome 1 (1p22.3).

The founding member TRPML1 is expressed in a number of tissues including adrenal gland, lung, bladder and placenta as well as in thymus, spleen and immune cells $(16,17)$. Mutations in this channel have been identified as responsible for the phenotype of Mucolipidosis type IV, a severe lysosomal storage disorder that displays cognitive, linguistic, visual and motor deficits (18-20). TRPML2 mRNA is mainly detected in lymphocytes and other cells of the immune system (21-24). No human or mouse disease phenotype has been demonstrated for this channel. TRPML3 is expressed in cochlear and vestibular sensory hair cells and melanocytes (25). Two spontaneous gain-of-function mutations in TRPML3 cause hearing loss and coat color dilution in mice (26-30). These mutations are known as varitint-waddler mutations (A419P and I362T).

TRPML1 is mainly localized in the lysosomes, where it promotes the cation efflux into the cytosol (31). In this way TRPML1 is involved in lysosomal storage, transportation and $\mathrm{pH}$ homeostasis. Indeed, TRPML1 mutations affect lysosomal storage and lysosomal impairment is responsible for autophagy defects. TRPML1 can also be negatively regulated by the target of rapamycin (TOR) with a consequent autophagy decrease supporting a central role of TRPML1 in this process (32). Moreover, oxidative stress through TRPML1 activation triggers autophagy to re-establish cellular redox homeostasis (33). TRPML1 regulates exocytosis of intracellular contents via the endosomal-lysosomal pathway $(34,35)$. In addition, TRPML1 plays a role in 
TABLE 1 | TRPMLs and cancer.

\begin{tabular}{|c|c|c|c|}
\hline & Tumor type & Effect & Reference \\
\hline \multicolumn{4}{|l|}{ TRPML1 } \\
\hline High expression & $\begin{array}{l}\text { Head \& Neck } \\
\text { Bladder }\end{array}$ & $\begin{array}{l}\text { HRAS activity } \uparrow \\
\text { Patient } \\
\text { prognosis } \downarrow\end{array}$ & (5) \\
\hline High expression & Melanoma & $\begin{array}{l}\text { MAPK and } \\
\text { mTORC1 } \downarrow \\
\text { Survival and } \\
\text { proliferation } \uparrow\end{array}$ & (6) \\
\hline High expression & High grade NSCLC & $\begin{array}{l}\text { Migration, } \\
\text { proliferation and } \\
\text { autophagy } \uparrow\end{array}$ & $(7)$ \\
\hline High expression & PDAC & OS and PFS $\downarrow$ & (8) \\
\hline High expression & TNBC & Cancer growth $\uparrow$ & (9) \\
\hline High expression & Endometrial & $\begin{array}{l}\text { Lysosomal } \mathrm{pH} \uparrow \\
\text { Imidazole } \\
\text { cytotoxicity } \downarrow\end{array}$ & $(10)$ \\
\hline $\begin{array}{l}\text { Loss expression } \\
\text { or reduction }\end{array}$ & GBM & OS $\downarrow$ & $(11)$ \\
\hline Activation & GBM & $\begin{array}{l}\text { Cell viability } \downarrow \\
\text { Apoptosis } \uparrow\end{array}$ & (11) \\
\hline \multicolumn{4}{|l|}{ TRPML2 } \\
\hline High expression & GBM & $\begin{array}{l}\text { Cell viability } \uparrow \\
\text { Apoptosis } \downarrow\end{array}$ & $(12)$ \\
\hline $\begin{array}{l}\text { Concurrent gene } \\
\text { in 16-gene } \\
\text { signature }\end{array}$ & Breast & Survival $\uparrow$ & (13) \\
\hline $\begin{array}{l}\text { Downregulation } \\
\text { due to DNA } \\
\text { methylation }\end{array}$ & $\begin{array}{l}\text { Acute Lymphoblastic } \\
\text { Leukemia }\end{array}$ & $\begin{array}{l}\text { Pro-tumoral } \\
\text { effects } \uparrow\end{array}$ & $(14)$ \\
\hline \multicolumn{4}{|l|}{ TRPML3 } \\
\hline $\begin{array}{l}\text { Decreased gene } \\
\text { expression }\end{array}$ & $\begin{array}{l}\text { High-risk PDAC patients, } \\
\text { KIRK }\end{array}$ & $\begin{array}{l}\text { Protective role, } \\
\mathrm{OS} \uparrow\end{array}$ & (15) \\
\hline $\begin{array}{l}\text { Decreased gene } \\
\text { expression }\end{array}$ & $\begin{array}{l}\text { Adenocortical, Breast } \\
\text { invasive, Endometrial, } \\
\text { Kidney Renal Papillary } \\
\text { Cell, Colon, Lung, Lung } \\
\text { Squamous Cell, Rectal, } \\
\text { Stomach, } \\
\text { Pheochromocytoma, } \\
\text { Paraganglioma, } \\
\text { Thymoma, Uterine } \\
\text { Carcinosarcoma }\end{array}$ & Not investigated & $(15)$ \\
\hline
\end{tabular}

$(\uparrow)$, increase; $(\downarrow)$ impairment.

metal ion homeostasis (36-39). TRPML2 and TRPML3 are expressed in early endosomes, late endosomes and lysosomes $(40,41)$; TRPML2 is also active in recycling endosomes $(42,43)$. It plays a direct role in chemokine secretion and thus modulates the inflammatory response. TRPML3 could be required for the autophagic process. Indeed, it is suggested that this channel, changing subcellular localization, provides $\mathrm{Ca}^{2+}$ during the autophagosome formation but the underlying mechanisms are not completely known $(40,44,45)$.

TRPMLs are activated by one of the major components of endolysosomal membranes, the phosphatidylinositol-3,5biphosphate (PtdIns(3,5)P2) (25, 46-49). Moreover, TRPML1 has an intraluminal loop whose protonation stimulates channel activation $(28,37,50)$. It is inhibited by phosphatidylinositol4,5-biphosphate (PtdIns(4,5)P2), sphingomyelins, and lysosomal adenosine $(48,49) . \mathrm{Na}^{+}$removal or less acidic/neutral $\mathrm{pH}$ activates TRPML3 and TRPML2, respectively (42, 43). Among the synthetic activators that are currently available, ML-SA1 activates TRPML1, TRPML2, and TRPML3 in humans; ML2SA1 is TRPML2 specific; MK6-83 activates TRPML1 and TRPML3 $(25,43,46,48)$. There are several synthetic inhibitors (ML-SIs); however, they are unable to discriminate the different TRPML isoforms $(33,35)$.

\section{TRPML1 AND CANCER}

In the last year several reports have linked increased TRPML1 expression to cancer. Among all, Jung et al. (5) demonstrated a correlation between human cancers with activating HRAS mutations and increased TRPML1 expression. In head and neck squamous cell carcinoma and bladder urothelial carcinoma, that display high rates of HRAS mutations, TRPML1 expression inversely correlates with patient prognosis. It was demonstrated that the enhancement in TRPML1 expression and activity in HRAS-driven cancer cells is required for localization of cholesterol in the plasma membrane. Indeed, its mislocalization from the plasma membrane to endolysosomes leads to loss of oncogenic HRAS from the cell surface and inhibition of downstream signaling. At the same time, TRPML1 inhibition decreases extracellular signal-regulated kinase (ERK) phosphorylation levels and cell proliferation.

The analysis of specific tumor types indicates that TRPML1 may exert different, and even opposite, functional activity in controlling tumor growth and progression.

Kasitinon et al. (6) have demonstrated that melanoma cells show a higher TRPML1 expression than normal melanocytes. In vitro and in vivo experiments revealed that loss of TRPML1 reduces melanoma cell growth in a xenograft model, but does not affect human melanocyte cell growth. However, in contrast to Jung et al. (5), Kasitinon et al. (6) reported that loss of TRPML1 leads to high phosphorylated MET and ERBB3 levels and thus MAPK activation in melanoma cells. The deregulation of these signaling pathways could be attributed to the reduced lysosomal degradation of growth factor receptors and the unique nature of melanomas. Moreover, TRPML1-deficient melanoma cells show, as a consequence of activated mTORC1 signaling, increased protein synthesis, unfolded protein response activation and cell death.

Pancreatic ductal adenocarcinoma (PDAC) patients characterized by worse overall survival and progression-free survival express high TRPML1 levels (8). In support of TRPML1 pro-tumoral role, its knockdown blocks the proliferation of PDAC cells in vitro and reduces the formation and growth of tumors in in vivo mouse models (8).

TRPML1 is upregulated in triple-negative breast cancer (TNBC) and its genetic down-regulation or pharmacological inhibition, suppresses TNBC growth. TRPML1 channel is involved also in controlling TNBC development by regulating 
mTORC1 activity and lysosomal ATP release via purinergic signaling pathways (9).

In human endometrial adenocarcinoma (HEC-1B) cells, TRPML1 overexpression inhibits vacuole formation and cell death induced by the lysosomotropic agent imidazole. In contrast, TRPML1 knockdown increases cell death induced by the same treatment (10). Thus, it was supposed that TRPML1 is able to protect against this kind of drug by regulating the $\mathrm{pH}$ of acidic organelles.

In contrast to the above-mentioned tumors, TRPML1 expression is decreased in human non-small-cell lung carcinoma (NSCLC) tissues compared to normal lung tissues (7). However, channel expression increases in advanced stages. These data suggest that MCOLN1 gene deletion supports tumorigenesis as a consequence of increased oxidative stress and genetic instability, while TRPML1 may confer a survival advantage in advanced tumors (7). In accordance with these findings, in vitro studies have demonstrated that TRPML1 silencing suppresses migration and proliferation of A549 and H1299 cancer cell lines. Instead, in transfected NSCLC cell lines, TRPML1 overexpression promotes autophagy. Collectively these findings indicate that, the loss of TRPML1 leads to a reduction in autophagic activity, which is essential for NSCLC survival and proliferation, while increase in TRPML1 expression is needed to keep metabolism and energy requirements of the tumor in balance (7).

In glioblastoma (GBM) patients loss or reduction of TRPML1 correlated with short survival, thus acting as negative prognostic factor (11). In vitro studies supported that TRPML1 activation, due to the agonist MK6-83, reduces cell viability and induces apoptosis (11). Strong oxidative stress may damage cellular constituents (e.g., mitochondria) permanently hence acting as a death signal. However, the generation of low ROS levels can act as survival signal, by triggering autophagy (33). In this regard, since the primary source of endogenous ROS are mitochondria, treating glioma cells with carbonyl cyanide m-chlorophenylhydrazone (CCCP), that is able to induce oxidative stress (33), stimulates a TRPML1dependent autophagy, as demonstrated by the ability of the autophagic inhibitor bafilomycin-A1, the TRPML1 inhibitor sphingomyelin, and MCOLN1 silencing, to inhibit the CCCPmediated effects (11).

\section{TRPML2 AND CANCER}

A link between TRPML2 expression and cancer has been investigated in different tumor types. A 16-gene signature, including MCOLN2 was found to be associated with distinct survival patterns in breast cancer patients (13).

In acute lymphoblastic leukemia patients, aberrant methylated regions are associated with altered expression of a set of genes (14). Among them, MCOLN2, affecting cell cycle processes, lymphocyte activation and apoptosis, has been found hypermethylated and downregulated. The function of TRPML2 in B lymphocytes is unclear; however, its transcriptional regulation by the B-cell lineage activator PAX5 and its expression in early immature B cells, may support for a role played by TRPML2 in the development of acute lymphoblastic leukemia.

Furthermore, the analysis of the transcriptome in colorectal cancer (CRC) showed that TRPML1 and TRPML2, detected in both normal and cancer cells, are significantly decreased in CRC cells. Noteworthy TRPML2 is dramatically down-regulated (51).

In GBM, TRPML2 was found to play different role than TRPML1 (12). TRPML2 is expressed in astrocytes, glioma tissues and high-grade glioma cell lines, with increased expression in GBM compared to pylocitic astrocytoma (grade I) (12). TRPML2 knockdown reduces proliferation by abrogating protein kinase B (AKT)/ERK1/2 phosphorylation and induces apoptosis in glioma cell lines. Overall, a pro-tumorigenic role of TRPML2 has been suggested (12).

\section{TRPML3 AND CANCER}

The role of MCOLN3 in cancer has been poorly investigated. By integrative analysis of multiple datasets, the MCOLN3 gene has been included in a 9-gene signature that is able to predict the overall survival of pancreatic cancer patients. The high-risk group expressing MCOLN3 is enriched with multiple oncological signatures and pathways involved in cancer aggressiveness and associated with significantly lower levels of $\mathrm{CD}^{+} \mathrm{T}$ cell infiltration (15).

Moreover, the data analysis, using The Cancer Genome Atlas (TCGA) database, showed that MCOLN3 is downregulated in several cancer types, and it is associated with a relatively better survival in kidney renal clear cell (15).

\section{DISCUSSION}

Heterogeneity of TRP channels expression is a feature of cancer cells and changes in their expression and functions are associated with neoplastic transformation and progression. We have just started to understand the genetic and epigenetic mechanisms controlling TRPML channel expression and endolysosomal $\mathrm{Ca}^{2+}$ signaling which seem to regulate cancer cell behavior. Nevertheless, several issues remain unsolved. How are TRPML channels regulated in cancer cells? TRPML homo/heteromerization or genic compensation is physiologically relevant in normal cells $(52,53)$, but what about in cancer cells? Currently it remains unclear in what aspects such interactions are physiologically relevant and what the physiological consequences would be when interfering with these interactions $(17,54)$. Moreover, which are the main TRPML ligands in cancer cells? Which is the contribution of immune cells expressing the TRPML channels in tumor microenvironment? And do the TRPML channels play a role in tumor escape?

Several studies describe that TRPML1 and TRPML2 represent suitable molecular targets in cancer. Thus, genetic manipulation or pharmacological modulation of TRPML expression and 
function could be regarded as a promising alternative anticancer therapy.

A genetic approach targeting TRPML expression could represent a good strategy. However, there is a potential for off-target effects linked with the ubiquitous expression of TRPML1 and the involvement of TRPML2 in immune functions. Moreover, loss of function mutations in MCOLN1 are responsible for the onset of neurological disorders. As suggested by Jung and Venkatachalam, the use of antisense oligonucleotides, unable to cross the blood-brain-barrier, may circumvent this problem (55).

The therapeutic approach is also hampered by a relative lack of TRPML selective agonists or antagonists; indeed, TRPML channels share high sequence similarity of about $75 \%$ at amino acid levels (56). Given the ability of PI(3,5)P2 to activate TRPMLs, researchers have also focused their efforts on the regulation of the PIKfyve/PI(3,5)P2 pathway in cancer. Studies conducted on hepatic cancer cell lines demonstrated the effectiveness of the inhibitor of $\mathrm{PI}(3,5) \mathrm{P} 2$ biosynthesis, YM201636, on attenuating cancer cell proliferation (57). Treatment with the PIKfyve inhibitor apilimod is able to induce cytotoxic effects in B-cell non-Hodgkin lymphoma and TFEB, the master transcriptional regulator of lysosomal biogenesis involved in a feedback loop with TRPML1 (58), regulates apilimod sensitivity (59).

Another level of complexity is related to the molecular mechanisms and signaling pathways acting both up- and downstream of TRPMLs. A role of mTORC1 and RAS-ERK as well

\section{REFERENCES}

1. Faris P, Shekha M, Montagna D, Guerra G, Moccia F. Endolysosomal Ca(2+) signalling and cancer hallmarks: two-pore channels on the move, TRPML1 lags behind! Cancers. (2018) 11:27. doi: 10.3390/cancers11010027

2. Parrington J, Lear P, Hachem A. Calcium signals regulated by NAADP and two-pore channels-their role in development, differentiation and cancer. Int J Dev Biol. (2015) 59:341-55. doi: 10.1387/ijdb.150211jp

3. Nguyen ONP, Grimm C, Schneider LS, Chao YK, Atzberger C, Bartel K, et al. Two-pore channel function is crucial for the migration of invasive cancer cells. Cancer Res. (2017) 77:1427-38. doi: 10.1158/0008-5472.CAN-16-0852

4. Grimm C, Bartel K, Vollmar AM, Biel M. Endolysosomal cation channels and cancer-A link with great potential. Pharmaceuticals. (2018) 11:4. doi: 10.3390/ph11010004

5. Jung J, Cho KJ, Naji AK, Clemons KN, Wong CO, Villanueva M, et al. HRASdriven cancer cells are vulnerable to TRPML1 inhibition. EMBO Rep. (2019) 20:e46685. doi: 10.15252/embr.201846685

6. Kasitinon SY, Eskiocak U, Martin M, Bezwada D, Khivansara V, Tasdogan A, et al. TRPML1 promotes protein homeostasis in melanoma cells by negatively regulating MAPK and mTORC1 signaling. Cell Rep. (2019) 28:2293-305.e9. doi: 10.1016/j.celrep.2019.07.086

7. Yin C, Zhang H, Liu X, Zhang H, Zhang Y, Bai X, et al. Downregulated MCOLN1 attenuates the progression of non-small-cell lung cancer by inhibiting lysosome-autophagy. Cancer Manag Res. (2019) 11:8607-17. doi: 10.2147/CMAR.S216538

8. Hu ZD, Yan J, Cao KY, Yin ZQ, Xin WW, Zhang MF. MCOLN1 promotes proliferation and predicts poor survival of patients with pancreatic ductal adenocarcinoma. Dis Markers. (2019) 2019:9436047. doi: 10.1155/2019/9436047 as Akt/PKB/ERK in TRPML1 $(6,60)$ and TRPML2-expressing tumor cells (12) has been proposed, although there are divergent findings in different cancer cell types. These opposite results may reflect distinct effects of TRPML on different cancer cells that could be due to distinctive mutations, for example HRAS signaling is mutated in head and neck cancer cells but not in melanoma cells $(6,61)$.

Overall, mucolipin targeting might represent a novel and innovative approach in the prognosis and therapy of different cancer types. Obviously, more in-depth studies are needed to completely reveal their potential in cancer therapy.

\section{AUTHOR CONTRIBUTIONS}

GS wrote the manuscript. MM, MS, OM, and FM revised the manuscript. $\mathrm{MM}$ and $\mathrm{OM}$ re-examined and revised the manuscript.

\section{FUNDING}

MM was supported by Umberto Veronesi Foundation (Postdoctoral Fellowship 2019) and PRIN 2017, MURST.

\section{ACKNOWLEDGMENTS}

The authors would like to thank Sheila Beatty for editing the English usage in the manuscript.

9. Xu M, Almasi S, Yang Y, Yan C, Sterea AM, Rizvi Syeda AK, et al. The lysosomal TRPML1 channel regulates triple negative breast cancer development by promoting mTORC1 and purinergic signaling pathways. Cell Calcium. (2019) 79:80-8. doi: 10.1016/j.ceca.2019.02.010

10. Liu Z, Zhao S, Wu S, Zhang J, Nie Z, Zeng S. A novel role of transient receptor potential mucolipin1 (TRPML1) in protecting against imidazole-induced cytotoxicity. Biochem Cell Biol. (2014) 92:279-86. doi: 10.1139/bcb-2014-0044

11. Morelli MB, Amantini C, Tomassoni D, Nabissi M, Arcella A, Santoni G. Transient receptor potential Mucolipin-1 channels in glioblastoma: role in patient's survival. Cancers. (2019) 11:525. doi: 10.3390/cancers11040525

12. Morelli MB, Nabissi M, Amantini C, Tomassoni D, Rossi F, Cardinali C, et al. Overexpression of transient receptor potential mucolipin-2 ion channels in gliomas: role in tumor growth and progression. Oncotarget. (2016) 7:4365468. doi: 10.18632/oncotarget.9661

13. Huang CC, Tu SH, Lien HH, Jeng JY, Huang CS, Huang CJ, et al. Concurrent gene signatures for han chinese breast cancers. PLoS ONE. (2013) 8:e76421. doi: 10.1371/journal.pone.0076421

14. Almamun M, Levinson BT, van Swaay AC, Johnson NT, McKay SD, Arthur GL, et al. Integrated methylome and transcriptome analysis reveals novel regulatory elements in pediatric acute lymphoblastic leukemia. Epigenetics. (2015) 10:882-90. doi: 10.1080/15592294.2015.1078050

15. Wu M, Li X, Zhang T, Liu Z, Zhao Y. Identification of a nine-gene signature and establishment of a prognostic nomogram predicting overall survival of pancreatic cancer. Front Oncol. (2019) 9:996. doi: 10.3389/fonc.2019.00996

16. Spix B, Chao Y, Abrahamian C, Chen C. TRPML cation channels in inflammation and immunity. Front Immunol. (2020) 11:225. doi: 10.3389/fimmu.2020.00225

17. Samie MA, Grimm C, Evans JA, Curcio-Morelli C, Heller S, Slaugenhaupt $\mathrm{SA}$, et al. The tissue-specific expression of TRPML2 (MCOLN-2) gene 
is influenced by the presence of TRPML1. Pflugers Arch. (2009) 459:7991. doi: 10.1007/s00424-009-0716-5

18. Bargal R, Avidan N, Ben-Asher E, Olender Z, Zeigler M, Frumkin A, et al. Identification of the gene causing mucolipidosis type IV. Nat Genet. (2000) 26:118-23. doi: $10.1038 / 79095$

19. Sun M, Goldin E, Stahl S, Falardeau JL, Kennedy JC, Acierno JS Jr, et al. Mucolipidosis type IV is caused by mutations in a gene encoding a novel transient receptor potential channel. Hum Mol Genet. (2000) 9:24718. doi: $10.1093 / \mathrm{hmg} / 9.17 .2471$

20. Bassi MT, Manzoni M, Monti E, Pizzo MT, Ballabio A, Borsani G. Cloning of the gene encoding a novel integral membrane protein, mucolipidin-and identification of the two major founder mutations causing mucolipidosis type IV. Am J Hum Genet. (2000) 67:111020. doi: 10.1016/S0002-9297(07)62941-3

21. Cuajungco MP, Silva J, Habibi A, Valadez JA. The mucolipin-2 (TRPML2) ion channel: a tissue-specific protein crucial to normal cell function. Pflugers Arch. (2016) 468:177-92. doi: 10.1007/s00424-015-1732-2

22. Valadez JA, Cuajungco MP. PAX5 is the transcriptional activator of mucolipin-2 (MCOLN2) gene. Gene. (2015) 555:194202. doi: 10.1016/j.gene.2014.11.003

23. Sun L, Hua Y, Vergarajauregui S, Diab HI, Puertollano R. Novel role of TRPML2 in the regulation of the innate immune response. J Immunol. (2015) 195:4922-32. doi: 10.4049/jimmunol.1500163

24. García-Añoveros J, Wiwatpanit T. TRPML2 and mucolipin evolution. Handb Exp Pharmacol. (2014) 222:647-58. doi: 10.1007/978-3-642-54215-2_25

25. Grimm C, Jörs S, Saldanha SA, Obukhov AG, Pan B, Oshima K, et al. Small molecule activators of TRPML3. Chem Biol. (2010) 17:13548. doi: 10.1016/j.chembiol.2009.12.016

26. DiPalma F, Belyantseva IA, Kim HJ, Vogt TF, Kachar B, Noben-Trauth K. Mutations in Mcoln3 associated with deafness and pigmentation defects in varitint-waddler (Va) mice. Proc Natl Acad Sci USA. (2002) 99:149949. doi: 10.1073/pnas.222425399

27. Grimm C, Cuajungco MP, van Aken AFJ, Schnee M, Jörs S, Kros CJ, et al. A helix-breaking mutation in TRPML3 leads to constitutive activity underlying deafness in the varitint-waddler mouse. Proc Natl Acad Sci USA. (2007) 104:19583-8. doi: 10.1073/pnas.0709846104

28. Xu H, Delling M, Li L, Dong X, Clapham DE. Activating mutation in a mucolipin transient receptor potential channel leads to melanocyte loss in varitint-waddler mice. Proc Natl Acad Sci USA. (2007) 104:183216. doi: 10.1073/pnas.0709096104

29. Nagata K, Zheng L, Madathany T, Castiglioni AJ, Bartles JR, García-Añoveros J. The varitint-waddler (Va) deafness mutation in TRPML3 generates constitutive, inward rectifying currents and causes cell degeneration. Proc Natl Acad Sci USA. (2008) 105:353-8. doi: 10.1073/pnas.07079 63105

30. Noben-Trauth K. The TRPML3 channel: from gene to function. Adv Exp Med Biol. (2011) 704:229-37. doi: 10.1007/978-94-007-026 5-3_13

31. Morgan AJ, Platt FM, Lloyd-Evans E, Galione A. Molecular mechanisms of endolysosomal $\mathrm{Ca}^{2+}$ signalling in health and disease. Biochem J. (2011) 439:349-74. doi: 10.1042/BJ20110949

32. Onyenwoke RU, Sexton JZ, Yan F, Díaz MCH, Forsberg LJ, Major MB, et al. The mucolipidosis IV $\mathrm{Ca}^{2+}$ channel TRPML1 (MCOLN1) is regulated by the TOR kinase. Biochem J. (2015) 470:331-42. doi: 10.1042/BJ20150219

33. Zhang X, Cheng X, Yu L, Yang J, Calvo R, Patnaik S, et al. MCOLN1 is a ROS sensor in lysosomes that regulates autophagy. Nat Commun. (2016) 7:12109. doi: $10.1038 /$ ncomms12109

34. LaPlante JM, Sun M, Falardeau J, Dai D, Brown EM, Slaugenhaupt SA, et al. Lysosomal exocytosis is impaired in mucolipidosis type IV. Mol Genet Metab. (2006) 89:339-48. doi: 10.1016/j.ymgme.2006.05.016

35. Samie $\mathrm{M}$, Wang $\mathrm{X}$, Zhang $\mathrm{X}$, Goschka $\mathrm{A}$, Li X, Cheng X, et al. A TRP channel in the lysosome regulates large particle phagocytosis via focal exocytosis. Dev Cell. (2013) 26:511-24. doi: 10.1016/j.devcel.2013. 08.003

36. Cuajungco MP, Basilio LC, Silva J, Hart T, Tringali J, Chen CC, et al. Cellular zinc levels are modulated by TRPML1-TMEM163 interaction. Traffic. (2014) 15:1247-65. doi: 10.1111/tra.12205
37. Dong XP, Cheng X, Mills E, Delling M, Wang F, Kurz T, et al. The type IV mucolipidosis-associated protein TRPML1 is an endolysosomal iron release channel. Nature. (2008) 455:992-6. doi: 10.1038/nature07311

38. Eichelsdoerfer JL, Evans JA, Slaugenhaupt SA, Cuajungco MP. Zinc dyshomeostasis is linked with the loss of mucolipidosis IV-associated TRPML1 ion channel. $J$ Biol Chem. (2010) 285:34304-8. doi: 10.1074/jbc.C110.16 5480

39. Kukic I, Lee JK, Coblentz J, Kelleher SL, Kiselyov K. Zinc-dependent lysosomal enlargement in TRPML1-deficient cells involves MTF-1 transcription factor and ZnT4 (Slc30a4) transporter. Biochem J. (2013) 451:15563. doi: 10.1042/BJ20121506

40. Kim HJ, Soyombo AA, Tjon-Kon-Sang S, So I, Muallem S. The $\mathrm{Ca}(2+)$ channel TRPML3 regulates membrane trafficking and autophagy. Traffic. (2009) 10:1157-67. doi: 10.1111/j.1600-0854.2009.00924.x

41. Martina JA, Lelouvier B, Puertollano R. The calcium channel mucolipin-3 is a novel regulator of trafficking along the endosomal pathway. Traffic. (2009) 10:1143-56. doi: 10.1111/j.1600-0854.2009.00935.x

42. Chen CC, Butz ES, Chao YK, Grishchuk Y, Becker L, Heller S, et al. Small molecules for early endosome-specific patch clamping. Cell Chem Biol. (2017) 24:907-16.e4. doi: 10.1016/j.chembiol.2017.05.025

43. Plesch E, Chen CC, Butz E, Scotto Rosato A, Krogsaeter EK, Yinan H, et al. Selective agonist of TRPML2 reveals direct role in chemokine release from innate immune cells. Elife. (2018) 7:e39720. doi: 10.7554/eLife.39720.022

44. Kim SW, Kim DH, Park KS, Kim MK, Park YM, Muallem S, et al. Palmitoylation controls trafficking of the intracellular $\mathrm{Ca}(2+)$ channel MCOLN3/TRPML3 to regulate autophagy. Autophagy. (2019) 15:32740. doi: $10.1080 / 15548627.2018 .1518671$

45. Kondratskyi A, Yassine M, Kondratska K, Skryma R, Slomianny C, Prevarskaya N. Calcium-permeable ion channels in control of autophagy and cancer. Front Physiol. (2013) 4:272. doi: 10.3389/fphys.2013. 00272

46. Chen CC, Keller M, Hess M, Schiffmann R, Urban N, Wolfgardt A, et al. A small molecule restores function to TRPML1 mutant isoforms responsible for mucolipidosis type IV. Nat Commun. (2014) 5:4681. doi: $10.1038 /$ ncomms5681

47. Dong X, Shen D, Wang X, Dawson T, Li X, Zhang Q, et al. PI(3,5)P(2) controls membrane trafficking by direct activation of mucolipin $\mathrm{Ca}(2+)$ release channels in the endolysosome. Nat Commun. (2010) 1:38. doi: $10.1038 /$ ncomms 1037

48. Shen D, Wang X, Li X, Zhang X, Yao Z, Dibble S, et al. Lipid storage disorders block lysosomal trafficking by inhibiting a TRP channel and lysosomal calcium release. Nat Commun. (2012) 3:731. doi: 10.1038/ncomms1735

49. Zhang X, Li X, Xu H. Phosphoinositide isoforms determine compartmentspecific ion channel activity. Proc Natl Acad Sci USA. (2012) 109:113849. doi: 10.1073/pnas.1202194109

50. Raychowdhury MK, González-Perrett S, Montalbetti N, Timpanaro GA, Chasan B, Goldmann WH, et al. Molecular pathophysiology of mucolipidosis type IV: $\mathrm{pH}$ dysregulation of the mucolipin-1 cation channel. Hum Mol Genet. (2004) 13:617-27. doi: 10.1093/hmg/ddh067

51. Pérez-Riesgo E, Gutiérrez LG, Ubierna D, Acedo A, Moyer MP, Núñez L, et al. Transcriptomic analysis of calcium remodeling in colorectal cancer. Int $\mathrm{J} \mathrm{Mol}$ Sci. (2017) 18:922. doi: 10.3390/ijms 18050922

52. Zeevi DA, Lev S, Frumkin A, Minke B, Bach G. Heteromultimeric TRPML channel assemblies play a crucial role in the regulation of cell viability models and starvation-induced autophagy. J Cell Sci. (2010) 123:311224. doi: $10.1242 /$ jcs. 067330

53. Guo Z, Grimm C, Becker L, Ricci AJ, Heller S. A novel ion channel formed by interaction of TRPML3 with TRPV5. PLoS ONE. (2013) 8:e58174. doi: 10.1371/journal.pone.0058174

54. Cheng X, Shen D, Samie M, Xu H. Mucolipins: intracellular TRPML1-3 channels. FEBS Lett. (2010) 584:2013-21. doi: 10.1016/j.febslet.2009.12.056

55. Jung J, Venkatachalam K. TRPML1 and RAS-driven cancers exploring a link with great therapeutic potential. Channels. (2019) 13:374-81. doi: 10.1080/19336950.2019.1666457

56. Puertollano R, Kiselyov K. TRPMLs: in sickness and in health. Am J Physiol Renal Physiol. (2009) 296:F1245-54. doi: 10.1152/ajprenal.90522.2008 
57. Hou JZ, Xi ZQ, Niu J, Li W, Wang X, Liang C, et al. Inhibition of PIKfyve using YM201636 suppresses the growth of liver cancer via the induction of autophagy. Oncol Rep. (2019) 41:1971-9. doi: 10.3892/or.2018.6928

58. Scotto Rosato A, Montefusco S, Soldati C, Di Paola S, Capuozzo A, Monfregola J, et al. TRPML1 links lysosomal calcium to autophagosome biogenesis through the activation of the CaMKK $\beta /$ VPS34 pathway. Nat Commun. (2019) 10:5630. doi: 10.1038/s41467-019-13572-w

59. Gayle S, Landrette S, Beeharry N, Conrad C, Hernandez M, Beckett $P$, et al. Identification of apilimod as a first-in-class PIKfyve kinase inhibitor for treatment of B-cell non-Hodgkin lymphoma. Blood. (2017) 129:1768-78. doi: 10.1182/blood-2016-09736892

60. Jung J, Venkatachalam K. TRPing the homeostatic alarm - Melanoma cells are selectively vulnerable to TRPML1 deletion. Cell Calcium. (2019) 84:102082. doi: 10.1016/j.ceca.2019.102082
61. Hodis E, Watson IR, Kryukov GV, Arold ST, Imielinski M, Theurillat JP, et al. A landscape of driver mutations in melanoma. Cell. (2012) 150:25163. doi: $10.1016 /$ j.cell.2012.06.024

Conflict of Interest: The authors declare that the research was conducted in the absence of any commercial or financial relationships that could be construed as a potential conflict of interest.

Copyright (๑) 2020 Santoni, Santoni, Maggi, Marinelli and Morelli. This is an openaccess article distributed under the terms of the Creative Commons Attribution License (CC BY). The use, distribution or reproduction in other forums is permitted, provided the original author(s) and the copyright owner(s) are credited and that the original publication in this journal is cited, in accordance with accepted academic practice. No use, distribution or reproduction is permitted which does not comply with these terms. 